\title{
Milton Hatoum: um escritor à espreita da linguagem Entrevista
}

O escritor amazonense Milton Hatoum diplomou-se em arquitetura na USP, trabalhou como jornalista cultural e foi também professor universitário no Brasil e no exterior. Em 1980, viajou como bolsista para a Espanha, onde morou em Madri e Barcelona. Autor do livro de contos $A$ cidade ilhada (2009), o escritor ganhou notoriedade com os romances Relato de um certo oriente (1989), Dois irmãos (2000), Cinzas do norte (2005) e Órfãos do eldorado (2008), todos publicados pela Companhia das Letras. Os três primeiros foram premiados com o Jabuti. Cinzas do norte ganhou os prêmios Portugal Telecom, APCA e Bravo!. Além disso, Milton Hatoum publicou a coletânea de crônicas Um solitário à espreita (2013) e, em 2017, o romance $A$ noite da espera. Sua obra foi traduzida em doze línguas e publicada em catorze países. Hatoum atuou também como cronista na extinta revista EntreLivros; no site Terra Magazine. Atualmente é colunista do Caderno 2 do jornal $O$ Estado de São Paulo.

Soletras: Sua primeira publicação editorial foi um livro de poesia, em 1979, Amazonas: palavras e imagens de um rio entre ruínas (10 anos antes do Relato de um certo Oriente). Por que não enfocou mais este gênero no desdobramento de sua carreira como escritor? Afinal, você pratica, vamos dizer assim, muito bem, outros gêneros, como crônica, conto e romance.

Milton Hatoum: Durante a minha vida de leitor, a poesia sempre esteve muito presente. Eu lia e ainda leio poesia brasileira e estrangeira. Até escrevi o prefácio da tradução de coletânea de poemas do poeta sírio Adonis, sem dúvida um dos maiores poetas vivos. Escrevo poemas na clandestinidade. Poderia publicar um livro, mas não é o caso. Percebi que a poesia é um gênero muito difícil para mim. Dentre as atividades artísticas, a poesia é a que diz mais com poucas palavras; o poema breve pode falar sobre uma coisa muito geral: "tenho duas mãos e o sentimento do mundo", todos conhecem esses versos do Drummond, que são de um alcance extraordinário. Aí eu praticamente fui

\footnotetext{
${ }^{1}$ Aídes José Gremião Neto é mestre em Estudos Literários pelo Programa de Pós-Graduação em Letras e Linguística da UERJ e membro do grupo de pesquisa "Poéticas da diversidade", cadastrado no CNPq. Email: aidesgremiaoneto@gmail.com
} 


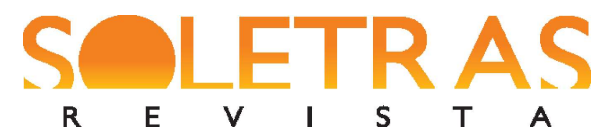

N. 38-2019.2- AÍDES JOSÉ GREMIÃO NETO

MILTON HATOUM

derrotado pela poesia; no livro (Amazonas: Palavras e imagens de um rio entre Ruínas) talvez haja um poema legível. Lembro que eu tinha uma professora na USP - eu estudava na FAU (arquitetura), mas assistia como ouvinte às aulas de teoria literária essa professora de literatura hispano-americana disse "aqui tem um poema que eu assinaria', é um poema breve, que está no fim do livro. Depois disso eu desencanei, disse: não, a poesia é uma coisa difícil. Um poeta é quase um iluminado; não falo de qualquer poeta, porque nesse país todo mundo escreve, até o presidente interino (Michel Temer) é poeta - agora não é mais interino. Mas aí eu pensei no primeiro romance como uma prosa que se aproximasse da poesia: a narrativa ficcional movida até certo ponto pelo lirismo; então eu mitiguei um pouco esse desejo de ser poeta com a prosa mais ou menos poética com Relato de um certo Oriente. A poesia também está muito presente no romance $A$ noite da espera. Alguns jovens querem ser poetas, e esse desejo passa pela leitura da boa poesia.

Soletras: Retomando rapidamente o que você mencionou: o que você entende por 'ser iluminado'?

M.H.: A poesia não é uma coisa totalmente pensada ou refletida, como o romance, que exige um trabalho diário com a linguagem, anos de trabalho... Claro que um poeta também é um artesão da linguagem, e isso se nota em qualquer poema. O João Cabral, avesso à ideia da inspiração, chamava de "trabalho de arte". Mas a poesia surge em algum momento, ela... é uma coisa inexplicável dos grandes poetas. O Bandeira, aquela coisa para mim é um milagre, como é que ele escreve aquilo? Como se fosse a coisa mais natural do mundo, mas gente sabe que é muito elaborado. $\mathrm{O}$ "alumbramento" bandeiriano, essa iluminação súbita é algo muito difícil, só mesmo esses iluminados. Um bom poema não pode ter falhas. Narradores, não. Quer dizer, um romance pode fraquejar aqui e ali, pode ser excessivo, às vezes. Romances sem falhas são difíceis, mas penso que há vários na nossa literatura. Grande Sertão: Veredas, São Bernardo, Vidas Secas, Lavoura Arcaica, Perto do Coração Selvagem são alguns exemplos. Uma ou outra acabam transcendendo o gênero literário, dando à ficção uma força lírica que só lemos nos grandes livros. A poesia exige uma síntese muito grande, quer dizer, ela é ao mesmo tempo breve e aponta para uma coisa mais geral, que é algo muito difícil, 


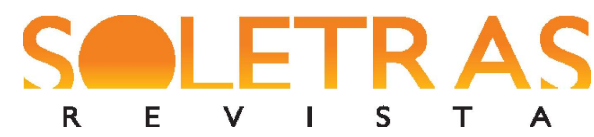

porque depende do ritmo, da melodia, da profundidade do sentido. Não se escolhe 'eu quero ser poeta', a poesia te procura, se impõe também. O caso do Drummond é exemplar, o cara conseguiu escrever aquilo; Vinícius... Todos os grandes poetas têm essa espécie de inspiração, que a gente pensa que é uma facilidade, mas não é; não há facilidade, mas a grande poesia só surge para algumas pessoas. O poeta Adonis, que eu citei antes... É impressionante como domina a linguagem, imprime um ritmo e cria imagens. Aos 87 anos, sempre é lembrado pela academia sueca para concorrer ao prêmio Nobel. Quando ele veio para a Flip, eu e o Alberto Mussa almoçamos com ele no Rio. Ele olhou para uma maçã e começou a falar em francês da forma da maçã, da cor, da textura, do equilíbrio, do erotismo que a maçã evoca... Para mim ele estava recitando um poema em francês, que nem é a língua dele, veja só, embora ele seja bilíngue. Só um poeta pode fazer isso, como o Bandeira fez: falar poeticamente de uma fruta, quase uma natureza morta, que se tornou viva pelas palavras. É isso: a poesia une sentimento e reflexão. No caso de João Cabral, é muito mais reflexão, trabalho com as palavras.

Soletras: Nos poemas de Amazonas: palavras e imagens de um rio entre ruínas parece ter tido isso.

M.H.: Lembro que eu lia muito João Cabral e outros brasileiros, mas a obra de João Cabral eu acompanhava de perto, lia e relia. Lia poetas norte-americanos, ingleses e franceses, poetas que eu tinha lido em Brasília, leituras indicadas por um embaixador que eu conheci lá, e que aparece nesse novo romance ( $A$ noite da espera). Um embaixador que era perseguido pela ditadura e vivia no ostracismo. Lá em Brasília, quando eu estudei no colégio de aplicação, ganhei um concurso de poesia; acho que foi por isso que eu me animei, mas eu tinha 16 anos. Esse poema foi publicado no Correio Braziliense, em 1969, salvo engano.

Soletras: Pode falar um pouco do Hatoum escritor e intelectual pré Relato de um certo Oriente? Ou melhor, conte de suas publicações no cenário da literatura - como é o caso desse poema mencionado por você -; onde elas foram veiculadas; onde elas 


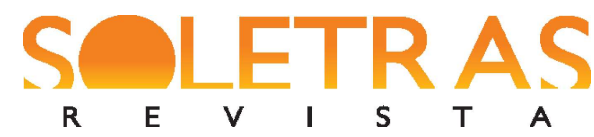

N. 38- 2019.2- AÍDES JOSÉ GREMIÃO NETO

MILTON HATOUM

podem ser encontradas; se elas foram/serão reescritas), de suas produções como intelectual, de seu percurso como leitor de ficção e da relação dessas leituras com sua escrita, principalmente no que tange ao gênero poesia.

M.H.: Eu publiquei pouquíssima coisa antes do Relato; publiquei esse poema de Brasília, republicado num livro da ex-diretora do colégio de aplicação, onde estudei. Depois, em São Paulo, eu fundei com alguns amigos da FAU a Poetação, uma revista de poesia e desenho, com traduções também. Nós éramos alunos de arquitetura, mas gostávamos de literatura, sobretudo eu e um amigo, o Horacio Costa, que hoje é professor da USP, tradutor, ensaísta e poeta. Ele ganhou o prêmio Jabuti com um livro de poesia. Essa revista durou pouco. Publicamos apenas quatro números; era uma edição muito artesanal. O artista plástico Rubens Matuck e a fotógrafa Rosely Nakagawa têm os números dessa revista. Depois publiquei poemas no livro Palavras e Imagens de um rio entre ruínas. Isso foi em 1978, 79, por aí. Publiquei também uma crônica no antigo Folhetim, da Folha de São Paulo. É uma longa crônica, só me lembro do título: "Papai Noel Visita a Amazônia", nunca pesquisei a Folha para resgatar esse texto. Além disso, publiquei artigos e reportagens quando fui free lancer da Isto é, dirigida pelo Mino Carta. Queria trabalhar, era estudante, e aí comecei a fazer fila na Isto é, fazia tudo, resenha de livro, artes plásticas, reportagens, entrevistas. Meu editor era o Nirlando Beirão, um ótimo jornalista. Cobri o lançamento do jornal Lampião, um jornal gay em plena ditadura. Fiquei surpreso quando meu texto apareceu no filme que eles fizeram. Escrevia sobre peças de teatro, de que gosto muito, fazia entrevistas com diretores, mas foi só isso que eu publiquei naquela época. Os contos que escrevi foram todos para o lixo; não gostei de nenhum, aí decidi rasgar tudo. Minha produção, meus textos anteriores ao primeiro romance são esses, não tinha muita coisa não. Ah, escrevi resenhas no "Leia Livros", lembro de uma sobre o romance Conversa na Catedral, do Vargas Llosa; e publiquei alguma coisa no "Jornal do Bairro", que pertencia à família do Raduan Nassar. Esse jornal tinha uma tiragem de 150 mil exemplares. Basicamente isso, não sei se há outras coisas.

Soletras: Seu leitor sabe da distância temporal entre suas publicações e do processo de escritura e reescritura que você mesmo admite existir. Esta pergunta é mais 
especificamente voltada para seu processo de escrita: sabemos quando uma cirurgia está pronta quando é realizada a sutura; e em relação ao romance, como sabe quando está terminado?

M.H.: Eu releio muito meus manuscritos; escrevo à mão, passo para o computador, depois imprimo, corrijo, releio, corrijo de novo... Há um momento de esgotamento físico e mental. Entrego o manuscrito para o editor e para os amigos que têm tempo de ler meus escritos; depois vou atrás dessas observações e, se há alguma coisa que eu possa melhorar, eu reescrevo. Esse processo demora bastante. O romance que menos demorou foi o Órfãos do Eldorado, pois no contrato com um editor escocês, eu me comprometia a entregar o manuscrito em 18 meses, mas acabei demorando mais de dois anos. Eu acho que o limite é físico e mental mesmo.

Soletras: Qual a importância do volume de crônicas da revista EntreLivros para seu projeto? Além disso, neste volume é o primeiro lugar onde você publica o gênero crônica?

M.H.: É. Na EntreLivros iniciei minha atividade como cronista regular. Foi uma experiência muito rica porque era um gênero praticamente desconhecido para mim; eu tive que enfrentar a pressão do tempo, da periodicidade, e entregar o texto no prazo; crônicas também mescladas com ensaios, mas eu acho que falei também de outros escritores, de coisas muito diferentes; mas foi minha primeira experiência como cronista assíduo. Depois entrei no Caderno 2, do Estadão, onde durante algum tempo publiquei crônicas quinzenais e agora eu escrevo mensalmente; tem gente que escreve uma crônica por dia, mas meu ritmo é totalmente diferente do jornalismo, embora o jornalismo tenha uma relação muito forte com o romance, que surgiu no século 18 , na Inglaterra; depois surgem os folhetins publicados na imprensa, sendo um gênero predominantemente burguês da sociedade industrializada da Europa Ocidental, um pouco diferente da Rússia, onde a industrialização era menor, mas ainda assim, foi o país que, junto com a França, produziu os grandes romances, contos e peças de teatro do século dezenove. 


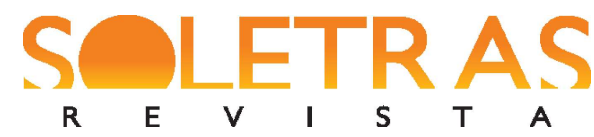

N. 38- 2019.2- AÍDES JOSÉ GREMIÃO NETO

MILTON HATOUM

Soletras: Aproveito para juntar as indagações a respeito dessa relação que o gênero crônica encerra: ou seja, entre o relato verossimilhante ao real, a imaginação e, no caso que você mesmo mencionou, o caráter ensaístico de algumas de suas crônicas do volume da EntreLivros. Como você balanceou tais aspectos no processo de escrita? Ainda relacionado a isso, por que tratar da própria matéria literária em uma perspectiva autoficcional em tais crônicas?

M.H.: Acho que em "Um Solitário à espreita" também. Muitas crônicas, na verdade, são quase exercícios de ficção, porque esboço alguns estudos de personagens, ou alusões a personagens de outros romances. Há uma crônica ambientada no Rio de Janeiro sobre a Alícia, do Cinzas do Norte. O editor separou as crônicas mais políticas de outras mais literárias. O resultado é uma salada de temas, mas a maioria das crônicas evoca lances da memória. $\mathrm{O}$ ensaio é diferente, porque visa ao estudo crítico, à análise ou interpretação crítica, mesmo sendo uma forma muito livre. O ensaio pede e até exige uma pesquisa, uma leitura da fortuna crítica, mas ao mesmo tempo o ensaísta tem uma liberdade e assume um risco, e assim se aproxima do ficcionista. Ele elege um objeto de estudo e escreve um texto que, às vezes, vai além de sua impressão sobre o livro. É um gênero muito interessante porque dá ao ensaísta liberdade de escrever sem as amarras e os jargões técnicos do academicismo... Ao mesmo tempo pretende se aproximar do objeto estudado, cercá-lo, tentar desvendar uma parte do enigma escondido no texto, sendo que o enigma não se decifra totalmente. Nas crônicas tento fugir do fato, de algo datado; às vezes, quando falo de política - e falo até a contragosto - diria que mesmo essas crônicas mais políticas, como as últimas que publiquei no Estadão, têm alguma coisa literária; elas puxam muito para a literatura. Tem uma recente chamada "Os Ratos". No começo falo do momento político, como se fosse uma carta de uma amiga francesa, e cito o vexame que foi a sessão do impeachment no congresso, mas no fim falo do romance Os ratos, do Dyonélio Machado, que é a história de um pobre diabo que está endividado, sem dinheiro para comprar leite. Sempre busco a literatura até para dar um pouco mais de consistência ao fato, se for o caso, mas ela se afasta do ensaio na medida em que o ensaio procura argumentar, analisar um texto. 


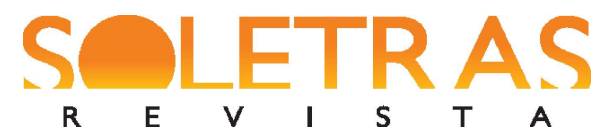

N. 38-2019.2- AÍDES JOSÉ GREMIÃO NETO MILTON HATOUM

Soletras: Então nós poderíamos dizer que há algumas que descambam mais para o lado ensaístico e outras que já fogem um pouco, embora ainda se relacionem?

M.H.: Sim. As crônicas da EntreLivros são mais próximas do ensaio, você tem razão, sobre alguns escritores que admiro. Nesse sentido, sim, se aproximam mais do ensaio totalmente despretensioso. Seria uma impressão de leitura de um leitor apaixonado por alguns livros. Não são muitas crônicas que tendem ao ensaio. Me lembro de uma em que eu falo também de um conto do Faulkner chamado "Sonhador e Soldados", sobre a guerra do Iraque, a invasão criminosa do Iraque pelo Bush filho. Quando estou muito impregnado pela leitura de livros de que gosto muito, vou por esse lado; um pouco como aconteceu nessa última "Obedecer é mais fácil do que entender", porque aqueles autores citados são muito caros para mim, como $A$ queda do céu, do David Kopenawa/Bruce Albert, que eu cito lá no fim.

Soletras: A metáforal alegoria do rio é um elemento presente em todo seu projeto literário. Poderia comentar um pouco essa questão?

M.H.: $\mathrm{Eu}$ nasci perto do rio Negro. Estive em Manaus agora gravando um documentário sobre Cinzas do Norte. Fui entrevistado pelo escritor Reinaldo Moraes, que depois publicou uma crônica chamada "Manaus não há mais". Ele me fez mais ou menos essa pergunta lá. Manaus é uma cidade banhada pelo Rio Negro, o maior afluente do Amazonas. O rio parece grande como o mar, diziam os cronista colonizadores. Os imigrantes sírios e libaneses chegaram à Amazônia nas últimas décadas do século XIX e começo do século passado; muitos foram atraídos pela economia do látex; outros, os cristãos, fugiam do Império Otomano. O rio Negro foi uma presença forte na minha infância, seja pela proximidade, seja pelas idas com meu pai ao mercado municipal Adolpho Lisboa. Ele saía de manhãzinha para comprar peixe e verduras; Manaus naquela época era uma cidade relativamente pequena, com uma população de 250 mil habitantes. Quando eu ia com ele ao mercado, uma bela arquitetura com estrutura de ferro, ficava vendo o movimento dos barcos, os peixes que chegavam, aquele cheiro, tudo aquilo foi importante na minha infância e, de algum 
modo, aparece em vários romances. E depois os passeios que comecei a fazer, as pescarias... Atravessava o rio e navegava por um furo, que é uma espécie de canal, que liga o Rio Negro aos lagos... Tudo isso ficou muito forte na minha memória. Que nem o Rio de Janeiro, onde o mar e as montanhas estão muito presentes. O que sentimos falta, no fundo, é disso: da paisagem humana e geográfica. Hoje o que me faz mais falta é a visão do rio e da floresta, mais do que da cidade, que foi destruída. O rio é metáfora, sempre foi, desde a poesia grega e latina: metáforas da passagem do tempo, o rio como espelho, a água como elemento purificador, como renascimento, como morte também; muitos símbolos que evocam uma dualidade estão presentes na água; a vida e a morte, a passagem da vida. Acho que não há poeta que não tenha falado do rio e do mar: dois dos grandes tópicos da literatura, a água e a viagem, epopeia e tragédia. O rio é também a metáfora da viagem, do deslocamento, da descoberta; além do que, para quem é da Amazônia, o rio é a estrada para toda vida, como disse Euclides da Cunha. Por isso nesse livrinho (Palavras e imagens de um rio entre Ruínas) o rio está presente o tempo todo.

Soletras: Eu diria em todos os seus livros.

M.H.: É, em todos os livros. E nesse novo romance que estou escrevendo tem um personagem chamado Nortista - o nome dele é Lélio, mas seu apelido é Nortista, porque ele é de lá. Aqui em São Paulo as pessoas chamam o Norte, referindo-se ao Nordeste; na verdade o Norte é a Amazônia; pro paulista o Norte é a Bahia. Então em qualquer lugar da Amazônia a presença do rio, mesmo nas capitais em que o rio é mais modesto, como o rio Acre, em Rio Branco, o rio é onipresente; é uma espécie de deus tutelar, líquido, que percorre a vida de todo mundo, quer dizer, sem o rio não chegariam os peixes, as frutas, a macaxeira (mandioca), os alimentos. Ele é profundamente ligado à vida indígena, à vida do caboclo, dos ribeirinhos. Isso é o que mais me emociona. Nessa visita para a entrevista em Manaus, eu falei 'vou com uma condição: que a produção faça, pelo menos, um breve passeio de bote, para vocês verem a cidade a partir do rio', que é a visão da narradora do Relato de um Certo Oriente. 


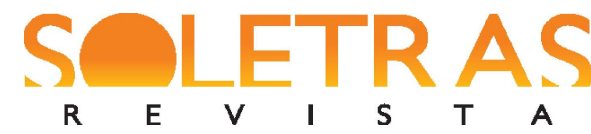

N. 38-2019.2- AÍDES JOSÉ GREMIÃO NETO

MILTON HATOUM

Soletras: Do fotógrafo Dorner também. Inclusive, no meu entendimento, acho que, na maioria das passagens que evidenciam a relação deste personagem como o rio, sua diç̧ão beira a prosa poética.

M.H.: É, porque são momentos quase epifânicos. O pequeno que às vezes se torna grande. São essas metáforas do rio que estão presentes na ficção, na própria espacialidade do romance. No Órfãos do Eldorado o rio, a calha do Amazonas, é o que une materialmente, isto é, é a estrada simbólica e real do Eldorado, o navio-cargueiro do pai, mas também essa ilha onde a moça se refugia. Ele simboliza e materializa o movimento, o palco móvel da novela. Não se pode pensar na Amazônia sem a presença da água e da floresta. E o rio é também, falando do nosso tempo, um rio em ruínas: as mineradoras, a poluição e o envenenamento da água, tudo isso aponta para o trágico, para o fim; porque para o trágico não há saída. A própria tragédia grega ensina isso, ou seja, o mundo sem saída. O rio tem uma presença forte na literatura; quando você falou do Faulkner, Palmeiras Selvagens tem toda uma parte que é ambientada no rio. Tem um momento que o presidiário, personagem desse romance, com a enchente do rio Mississipi, é enviado para resgatar e salvar as pessoas num bote, e toda essa narrativa, que são duas aparentemente separadas, paralelas com capítulos alternados, trata também da loucura, do desespero, dessas vidas desesperadas, do presidiário que salva as vidas da enchente do Mississipi e do casal que se separa, com um desenlace trágico. E aí é como se essa força quase telúrica do Mississipi arrastasse todas essas vidas, numa espécie de grande palco móvel da tragédia. O rio aparece também em alguns contos da Cidade Ilhada. Por exemplo, "Um Oriental na Vastidão", que é a história de uma mulher que recebe as cinzas de um cientista japonês. Ela conheceu esse cientista quando ele visitou a Amazônia, Manaus; anos depois ela recebe uma caixa, e aí ela recebe uma carta para que as cinzas do morto sejam jogadas no rio. Eu acho que em outros também há a presença do rio, como "Varandas da Eva". O rio era um elemento muito presente em Manaus na minha infância e juventude, porque os igarapés - em tupi significa “caminhos estreitos", mas muitos deles não eram tão estreitos assim - entravam em Manaus, formando balneários, aonde a gente ia nos fins de semana, clube de campos particulares e balneários públicos. Então, a presença da água na cidade - que o Reinaldo fala nessa crônica, uma Veneza amazônica, com os canais - é muito forte. 


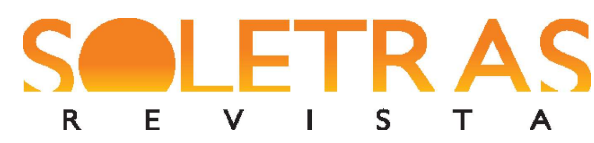

N. 38- 2019.2- AÍDES JOSÉ GREMIÃO NETO

MILTON HATOUM

Todos esses canais foram aterrados. Isso não é diferente do que aconteceu em São Paulo, porque aqui havia muitos rios e há dezenas de rios subterrâneos, rios que foram aterrados, sobraram esses esgotos a céu aberto, o Tietê, o Pinheiros... Com a zona franca, centenas de indústrias se instalaram em Manaus, a migração para lá foi maciça, as favelas se multiplicaram, os igarapés foram todos poluídos e depois aterrados, não sobrou mais nada. Menos o Rio Negro, porque esse é difícil matar, vai demorar, porque é muito grande. O importante na literatura é transformar tudo isso em linguagem, quer dizer, às vezes, se a literatura não expressar uma experiência de vida e de leitura, é difícil, ela não vinga. Hoje você vê muita coisa sendo escrita às pressas, sem muita elaboração, sem a experiência do narrador. Essa experiência é tudo, não dá pra ser superficial; e o romance pede isso, uma experiência de vida, que depois será filtrada, inventada, quer dizer, todo esse acúmulo de sabedoria, de experiência vivida, que traz o narrador. Não se trata da erudição; é importante ler os grandes livros; mas se trata, sobretudo, de um saber vivido também, um saber profundo, que você é capaz de transformá-lo em linguagem. Quando o Guimarães escreveu Grande Sertão, a quantidade de anotações que ele fez, de histórias que ele ouviu, tudo isso levou tempo. O romance é formado de contos ou histórias, as veredas que compõem o magma, a imensa massa rochosa: o grande sertão de palavras.

Soletras: As histórias que ficam intercaladas no entremeio da narrativa principal, digamos assim, são muito bem interligadas, uma puxa a outra. Já que você mencionou algumas de suas experiências de vida, em uma de suas entrevistas, você fala sobre um romance que, na época da Ditadura Militar, você chegou a escrever e jogou fora, porque ele estava muito próximo da experiência palpável e, talvez, você não tenha conseguido digeri-lo em linguagem. Nesse novo romance que você falou que menciona a ditadura talvez com mais ênfase, não sei, será que já há esse distanciamento temporal?

M.H.: Eu imagino que sim. O lado documental existe, porém não é muito forte. Quer dizer, não há um relato histórico sobre aquele momento. Nenhum narrador, nenhuma personagem fala ostensivamente sobre o que estava acontecendo. Tem apenas um relato 


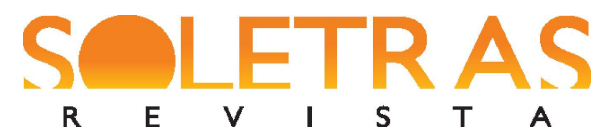

N. 38-2019.2- AÍDES JOSÉ GREMIÃO NETO

MILTON HATOUM

sobre tortura que não é direto, ele fala do sentimento da personagem, da morte da alma. Mas, para mim, esse distanciamento foi fundamental. O Cinzas do Norte, vamos dizer, foi uma primeira tentativa de falar sobre essa época, mas não é um romance político; o que prevalece não é o lado histórico, o lado político da ditadura, mas a história e a política estão lá. Nesse novo romance (A noite da espera) não poderia escrever como o Dois Irmãos ou como o Cinzas do Norte, um romance, digamos, com essa estrutura. Quando eu encontrei a forma, encontrei o romance que queria escrever. A forma que encontrei foi trabalhar com uma narrativa de diários, anotações e cartas de vários personagens. Há um narrador principal, que se corresponde com a mãe, e faz anotações esparsas sobre a vida dele e sua relação com os amigos. E há cartas de amigos e diários de amigos. Isso será ampliado no segundo volume da trilogia. No fundo, quis fazer uma pesquisa de vidas, de personagens... Algumas viveram juntas, outras se conhecem menos, e fica tudo um pouco disperso. É por essa razão que é um romance diferente, ele não tem um desfecho propriamente dito. Ele tem uma estrutura que lembra uma árvore ou os rios da Amazônia, com vários afluentes; mas tem um eixo, uma questão central do narrador, que não é resolvida.

Soletras: Talvez nem tivesse como, não é?

M.H.: É. Não há como. Fica para o leitor imaginar. E 'O Lugar Mais Sombrio', do título, pode ser muitas coisas, como o amor, a busca de um outro amor, pode ser a morte, pode ser a política, pode ser o país naquele momento, pode ser também o 'sombrio' numa imagem mais bíblica até, não tão obscura, mas pode ser o que esteja escondido também, oculto de alguma forma. É uma tentativa... A gente nunca sabe a reação do leitor. Mas certamente é muito diferente de tudo que eu já escrevi. Talvez seja bom também; pode assustar alguns leitores, mas pode também atrair outros. A gente não escreve pensando no leitor, escreve pensando nesse mundo que estamos inventando; escreve com ele, dentro dele; como se diz em espanhol: 'desde', de dentro de alguém ou de algo. 


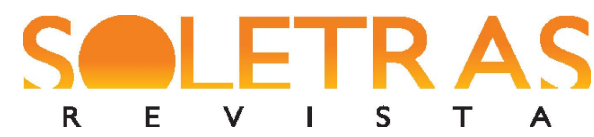

N. 38-2019.2- AÍDES JOSÉ GREMIÃO NETO MILTON HATOUM

Soletras: Para finalizar, em seu livro Amazonas: palavras e imagens de um rio entre ruínas há uma apresentação elaborada por você, a qual faz um recorte da história do Amazonas, desde o século XVI, com o início da colonização. Esse recorte temporal também está presente em suas narrativas. Trata-se de um projeto de escrita? Se sim, pode comentar?

M.H.: Eu não fiz isso conscientemente. Já me alertaram para isso uma vez, mas eu, para ser honesto, não tinha ideia do que eu ia escrever ainda, depois desse livrinho. Eu sabia que eu poderia escrever sobre a Amazônia, sobre Manaus, sobre a minha infância, algum drama familiar, mas eu não tinha ideia desses recortes históricos. Um crítico uma vez chamou o Relato, o Dois Irmãos e o Cinzas de trilogia, não sei até que ponto isso pode ser constatado. O que surgiu a partir do Relato, aí sim isso foi consciente - até porque o Relato é um romance que trabalha muito com a memória da narradora e dos outros, mas é um romance muito cerrado, quase tudo acontece na casa, no âmbito da família, nos dramas familiares. Manaus aparece muito pouco. Depois houve um movimento consciente de expansão, mas isso foi quando eu voltei à Manaus em 1984 e fiquei muito tempo lá; vivenciei a cidade, vi muitos espaços da minha infância e juventude sendo destruídos - isso para mim foi bastante chocante, porque eu tenho muito apego ao espaço, à história do lugar. O lugar, a história e a geografia sensíveis são importantes, e quando se destrói o lugar destroem-se a história, a relação entre as pessoas, a memória da cidade. Então o Dois Irmãos eu já pensei como uma possibilidade de expansão do drama familiar, da casa para a cidade de Manaus, com algumas incursões em São Paulo, um dos gêmeos vem para São Paulo, um deles rouba dólares do irmão e viaja para os Estados Unidos...

Soletras: Ao mesmo tempo parece que tem uma questão de cunho histórico ligada à nação.

M.H.: Sim, claro. A industrialização em São Paulo; esse clichê dos paulistas que pensam que São Paulo é a locomotiva do Brasil, em contraposição à região amazônica, à floresta, ao 'primitivo', ao mundo telúrico, ao mundo das origens. Tentei explorar essa 


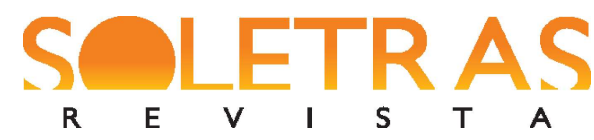

N. 38- 2019.2- AÍDES JOSÉ GREMIÃO NETO MILTON HATOUM

oposição civilização x barbárie, mas que sempre troca de lado, né. Como disse o Walter Benjamin na tese sobre História: "Não há um documento da civilização que não seja também um documento da barbárie”. E isso está na cabeça do engenheiro Yaqub, que quer que Manaus cresça e se torne uma metrópole, uma pequena São Paulo do Norte. De fato, Manaus cresceu muito, mas foi um crescimento "à gandaia", como disse Euclides da Cunha, já em 1905, em um dos ensaios, se não me engano, do livro Paraíso Perdido. Ele percebeu isso em Manaus, a cidade do "aventureiro solerte"; ele chama Manaus de uma cidade "comercial e insuportável", ao mesmo tempo "cosmopolita e caipira"; caipira porque ele está falando dos caboclos. Nessa época (1905) muitos manauaras falavam nheengatu. Todos os grandes monumentos arquitetônicos e toda a infraestrutura urbana (redes de água e esgoto, eletricidade, bondes, o porto) já tinham sido construídos. Uma cidade de trinta mil habitantes, altamente sofisticada, europeizada e ao mesmo tempo indígena e cabocla. Claro, os indígenas e mestiços não usufruíam dessa modernidade, que sempre foi para poucos, e não apenas em Manaus, mas no Brasil todo. Então no Dois Irmãos eu tentei trabalhar com esse tema civilização versus barbárie, que são inseparáveis. O Estado Islâmico que degola pessoas... Mas a guilhotina foi inventada pelos franceses; no século dezoito era uma prática comum, sempre degolaram. Muitos membros do Exército Islâmico são europeus, nasceram na Inglaterra, na França, na Bélgica. Como disse um escritor francês o "Estado Islâmico é um caso europeu". É importante parar para pensar no que alguns correspondentes no Oriente Médio, como o britânico Robert Fisk, escrevem sobre o terrorismo islâmico. Esse terror deve ser totalmente condenado, é um movimento fundamentalista ultrarreacionário, mas Fisk, como todo jornalista honesto, cita também o terrorismo de Estado. Ele escreveu algo assim: "Não se pode esquecer que milhões de argelinos morreram na guerra de libertação da Argélia, e que as águas do rio Sena já foram cobertas por cadáveres de argelinos; os franceses ficavam olhando os cadáveres dos argelinos; você acha que essas gerações esqueceram essa barbárie?! Os netos e bisnetos não se esquecem disso". Então, para falar da civilização na Europa, é preciso não se esquecer da barbárie... A gente pode falar das grandes artes e dos grandes artistas, mas é preciso falar também do que foi a Europa; da história de guerras, de atrocidades, de dominação, de conquistas, de espoliação. A mesma coisa vale para os Estados Unidos 


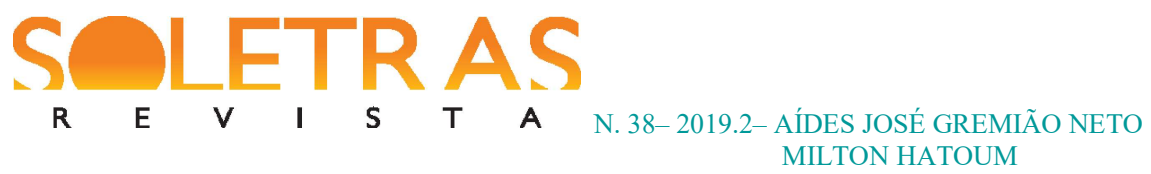

no século passado e mesmo agora. Então, como dizia o Machado, 'eu posso aceitar tudo, menos ser empulhado'. Voltando à sua pergunta, no Cinzas do Norte, essa expansão foi maior ainda. Eu tentei fazer do personagem Mundo um personagem que sai da província e percorre o mundo; morre no Rio de Janeiro, mas antes vai à Berlin, vai à Londres, tenta se afirmar como artista, mas havia uma dificuldade ou, para o Mundo, uma impossibilidade de ser artista naquela época. Tudo isso faz de Manaus um núcleo a partir do qual os personagens saem ou para o Brasil ou para fora do Brasil. No fundo tem um pouco a ver com a minha história... Saí muito jovem de Manaus e fui para Brasília. O Cinzas do Norte é o romance mais autobiográfico, isto é, o que mais se aproxima da minha vida, que mais tem a ver comigo, embora tudo ali seja construído. Isso também está nos contos, com alguns personagens nômades... A moça do conto "Bárbara no Inverno"... Ela vai morrer no Rio, na volta para casa. Esse conto foi inspirado numa música do Chico e do Francis Hime chamada "Atrás da Porta". Esse foi um conto que fiz por encomenda, para falar dessa belíssima canção, e também da minha vida de expatriado em Paris. A semente da trilogia "O lugar mais sombrio" está nesse conto.

Entrevista concedida em 23 de julho de 2019. 